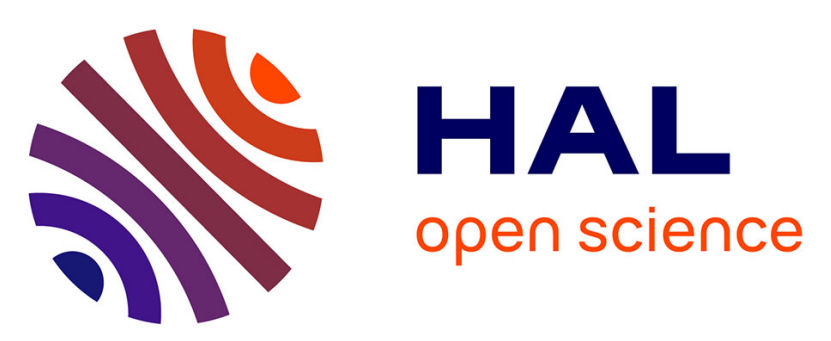

\title{
CharKey: An electronic identification key for wood charcoals of French Guiana
}

Stéphanie C Bodin, Rita Scheel-Ybert, Jacques Beauchêne, Jean-François Molino, Laurent Bremond

\section{To cite this version:}

Stéphanie C Bodin, Rita Scheel-Ybert, Jacques Beauchêne, Jean-François Molino, Laurent Bremond. CharKey: An electronic identification key for wood charcoals of French Guiana. IAWA Journal, 2019, 40 (1), pp.75-S20. 10.1163/22941932-40190227 . hal-03208719

\section{HAL Id: hal-03208719 \\ https://hal.science/hal-03208719}

Submitted on 27 Apr 2021

HAL is a multi-disciplinary open access archive for the deposit and dissemination of scientific research documents, whether they are published or not. The documents may come from teaching and research institutions in France or abroad, or from public or private research centers.
L'archive ouverte pluridisciplinaire HAL, est destinée au dépôt et à la diffusion de documents scientifiques de niveau recherche, publiés ou non, émanant des établissements d'enseignement et de recherche français ou étrangers, des laboratoires publics ou privés. 


\title{
CharKey: An electronic identification key for wood charcoals of French Guiana
}

\author{
Stéphanie C. Bodin ${ }^{1, *}$, Rita Scheel-Ybert ${ }^{2}$, Jacques Beauchêne ${ }^{3}$, \\ Jean-François Molino ${ }^{4}$, and Laurent Bremond ${ }^{1,5}$ \\ ${ }^{1}$ ISEM, Université Montpellier, CNRS, EPHE, IRD, Montpellier, France \\ 2Programa de Pós-Graduação em Arqueologia, Museu Nacional, \\ Universidade Federal do Rio de Janeiro, Brazil \\ ${ }^{3}$ CIRAD, UMR ECOFOG, F-97387, Kourou, Guyane, France \\ ${ }^{4}$ AMAP, IRD, CIRAD, CNRS, INRA, Université Montpellier, Montpellier, France \\ 5 École Pratique des Hautes Études, PSL Research University, Paris, France \\ *Corresponding author; e-mail: stephanie.bodin@umontpellier.fr
}

Accepted for publication: 2 October 2018 - Available online: December 2018

\begin{abstract}
Tropical tree floras are highly diverse and many genera and species share similar anatomical patterns, making the identification of tropical wood charcoal very difficult. Appropriate tools to characterize charcoal anatomy are thus needed to facilitate and improve identification in such species-rich areas.

This paper presents the first computer-aided identification key designed for charcoals from French Guiana, based on the wood anatomy of 507 species belonging to 274 genera and 71 families, which covers respectively $28 \%, 67 \%$ and $86 \%$ of the tree species, genera and families currently listed in this part of Amazonia. Species of the same genus are recorded together except those described under a synonym genus in Détienne et al. (1982) that were kept separately. As a result, the key contains 289 'items' and mostly aims to identify charcoals at the genus level. It records 26 anatomical features leading to 112 feature states, almost all of which are illustrated by SEM photographs of charcoal. The descriptions were mostly taken from Détienne et al.'s guidebook on tropical woods of French Guiana (1982) and follow the IAWA list of microscopic features for hardwood identification (Wheeler et al. 1989). Some adjustments were made to a few features and those that are unrelated to charcoal identification were excluded. The whole tool, named CharKey, contains the key itself and the associated database including photographs. It can be downloaded on Figshare at https://figshare. com/s/d7d40060b53d2ad60389 (doi: 10.6084/m9.figshare.6396005). CharKey is accessible using the free software $\mathrm{Xper}^{2}$, specifically conceived for taxonomic description and computer aided-identification.
\end{abstract}

Keywords: Charcoal anatomy, anthracology, $\mathrm{Xper}^{2}$, tropical flora, computeraided identification.

Note: Supplementary material can be accessed in the online edition of this journal via http://booksandjournals.brillonline.com/content/journals/ 


\section{INTRODUCTION}

Anthracology, the science dedicated to the study of carbonized wood, is a powerful method to reconstruct past vegetation (e.g. Heinz \& Thiébault 1998; Talon et al. 1998; Scheel-Ybert et al. 2003; Touflan et al. 2010) or to infer past fire-related human activities (e.g. Bal et al. 2010; Morin-Rivat et al. 2014; Scheel-Ybert et al. 2014). As such, anthracology plays a major role in paleoecological and archeological studies. It is mostly based on the identification of wood charcoal found in natural sediments or in archeological contexts. Although anthracology has been widely used in temperate regions since the 1970s, studies in tropical areas are more recent and far less numerous (for a review see Scheel-Ybert \& Gonçalves 2017). As a result, descriptions of charcoal anatomy as well as studies aiming to improve identification in areas of extreme diversity are still scarce (e.g. Hubau et al. 2012; Hubau et al. 2013; Scheel-Ybert \& Gonçalves 2017; Höhn \& Neumann 2018). In tropical South America, anthracological studies have mostly been conducted in Brazil by Rita Scheel-Ybert since the late 1990s while other parts of Amazonia, including the Guiana Shield where endemism is present, remain poorly studied. To our knowledge, no anthracological studies have been conducted in the Guianas since the pioneer work of Christophe Tardy in French Guiana twenty years ago. Hence, there is a need to improve charcoal identification in this species-rich area.

Since most of the anatomical characteristics of wood are preserved after carbonization and most can be used for charcoal identification, Neotropical anthracologists usually rely on wood anatomy atlases (Détienne \& Jacquet 1983) or identification guidebooks (Dechamps 1979, 1980, 1985). But because of the high species diversity of tropical tree flora, and the similarity of anatomical patterns among species of the same genus and even among genera of the same family, computer-aided keys are undoubtedly much more efficient than atlases. In this sense, the InsideWood online database (2004onwards; Wheeler 2011), which contains over 1,600 anatomical descriptions and images of taxa occurring in tropical South America, is an important identification tool for neotropical anthracologists. However, despite its usefulness for anthracology, InsideWood includes several features that are difficult to observe or absent from charcoal. Some microscopic features become less visible (e.g. vestured and bordered pits, tanniferous tubes or the number of bars in scalariform perforation plates) because of carbonization or taphonomy (Hubau et al. 2012); macroscopic, mechanical and organoleptic characteristics can no longer be perceived and measurements of quantitative features may substantially differ from those made in wood. In addition to these issues, InsideWood uses the broadly defined geographic features of the IAWA Hardwood list, e.g. Feature 186, Tropical South America, which includes many species not present everywhere within tropical South America. Checking which species actually occur in a given area and sorting relevant features when identifying an unknown sample can make the identification process very time consuming. As such, when research is conducted in targeted geographical areas, local keys that focus only on the features that are useful for anthracology can simplify and speed up the identification process.

Ideally, charcoal identification keys should be directly generated from anthracological atlases and collections rather than from descriptions of wood, but describing and databasing all the taxa included in such collections is extremely time consuming 
(Dotte-Sarout 2011). As a matter of fact, the first neotropical anthracological atlas was only published recently (Scheel-Ybert \& Gonçalves 2017). Along with - and based on - such fundamental works, computer-aided identification keys dedicated to charcoal will help improve anthracological studies.

Here we present the first computer-aided identification key dedicated to wood charcoal in French Guiana. It is based on anatomical descriptions of 507 species recorded under 274 genera and covering 71 families, representing respectively $28 \%, 67 \%$ and $86 \%$ of the tree species, genera and families currently listed in this region (Molino et al. 2009; Molino et al. unpublished data). The selected features mostly follow the IAWA list of microscopic features for hardwood identification (Wheeler et al. 1989) and nearly all are illustrated with photographs of charcoal using a SEM at the Electron and Analytical Microscopy Platform, University of Montpellier (France).

\section{CONSTRUCTION OF THE IDENTIFICATION}

\section{Source data}

The key is primarily based on anatomical features described in the guidebook on Guianan woods by Détienne et al. (1982). When the species descriptions in the guidebook were incomplete, the missing information was taken from the more general atlas on Amazonian woods by Détienne \& Jacquet (1983) and from the InsideWood online database (2004-onwards; Wheeler 2011). Lastly, unknown information symbolized in InsideWood by a question mark was provided by two different charcoal reference collections: a large one from Brazil, assembled by Rita Scheel-Ybert and a more restricted Guianan collection first assembled by Christophe Tardy. Both belong to the largest wood charcoal collection of the world (Scheel-Ybert 2016), located at the Institut des Sciences de l'Evolution (Montpellier, France). The Guianan collection is now being enriched with new species, notably by charring wood samples provided by the Wood Sciences Laboratory of UMR ECOFOG (Kourou, French Guiana).

\section{Key format}

The key is first built as a matrix with species/genera in horizontal rows and anatomical features in columns. Since most wood anatomical characters are preserved during carbonization, the majority of IAWA features were included in the key. Nevertheless, some features were set aside or refined depending on their relevance for charcoal identification (see Charcoal anatomical features section). Eighty percent of the features are illustrated by SEM photographs: most are of charcoals from the Guianan collection and the remaining photos show either specimens from the Brazilian collection or are archeological material. In this first version of the key, we aimed to illustrate the maximum possible number of features, and nearly all are illustrated by at least one photo. More will be added in the next version for better representativeness of the taxa described.

The whole tool, named CharKey, contains the key itself and the related database, including the photographs. It was designed and must be accessed with $\mathrm{Xper}^{2}$, a free software specifically conceived for taxonomic description and computer-aided identification (Ung et al. 2010). Several versions of $\mathrm{Xper}^{2}$ (Windows, Linux, MacOS) are available at http://www.infosyslab.fr/?q=en/resources/software/xper2. 

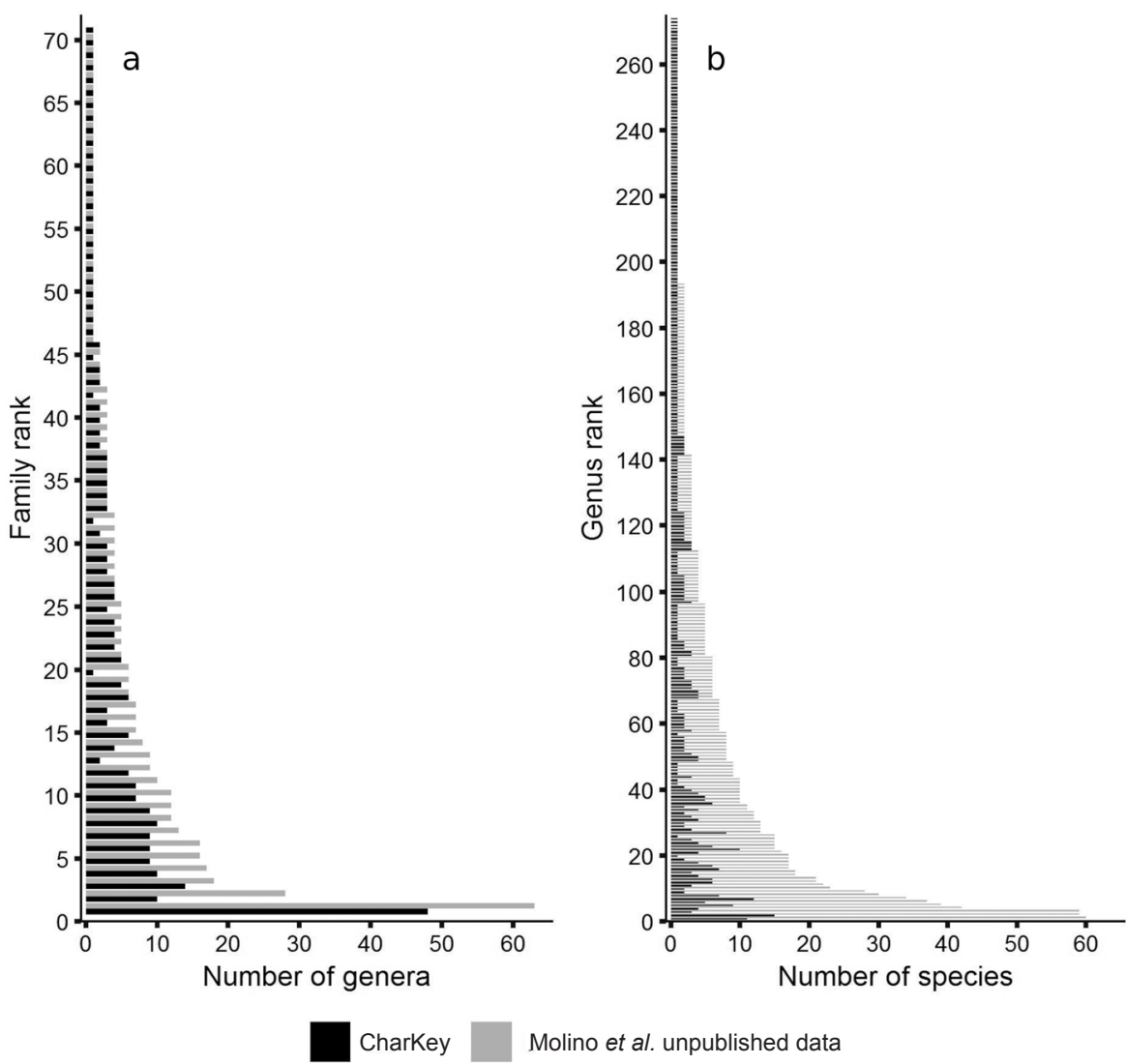

Figure 1. - a: Number of genera per family in CharKey compared with the updated checklist of Molino et al. (unpublished data). Menispermaceae (rank 71) are not in the checklist because they do not reach a dbh $\geq 10 \mathrm{~cm}$. $-\mathrm{b}$ : The genera absent from the checklist, corresponding to ranks 271 to 274, are Artocarpus, Gmelina (both introduced), Abuta and Machaerium (lianas with a dbh $<10 \mathrm{~cm}$ ). The detailed lists of genera and species with their ranking can be found in the Supplementary Material.

\section{Taxonomic spectrum}

The list of species included in CharKey is presented in Supplementary Material. In addition to those described in Détienne et al. (1982), this list includes 37 species described only in Détienne \& Jacquet (1983) which are amongst the 1,700 native

Figure 2. - a: Appearance of CharKey under $\mathrm{Xper}^{2}$ when launched. When the user clicks on a descriptor (1) its states appear in the top right window and its definition in the bottom left window. The pictures illustrating each state can be seen by clicking on one of them (2), then on the "Image" tab (3). To start the identification process, click on "identification" in the tool bar at the top of the screen (4). - b: Identification window. To start the process, select a descriptor (5) and at least one state (6). Note that the logical operator can be chosen (7). When the user 


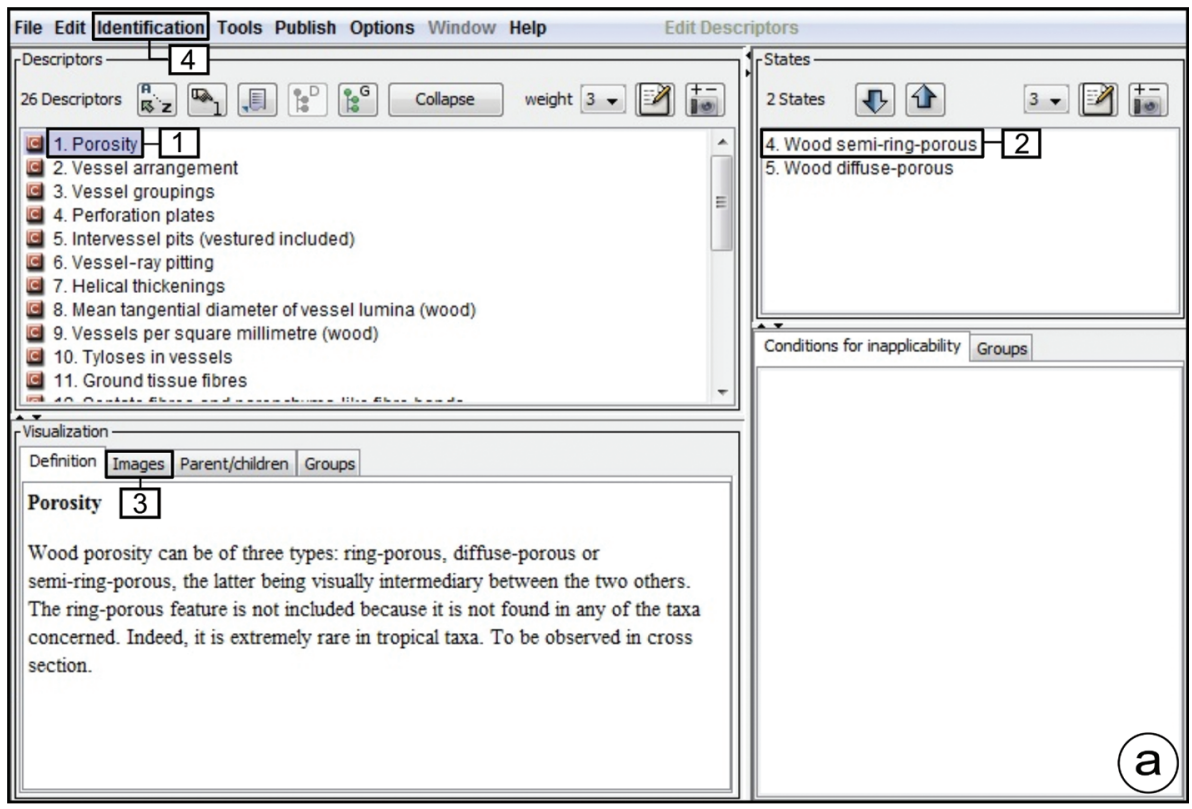

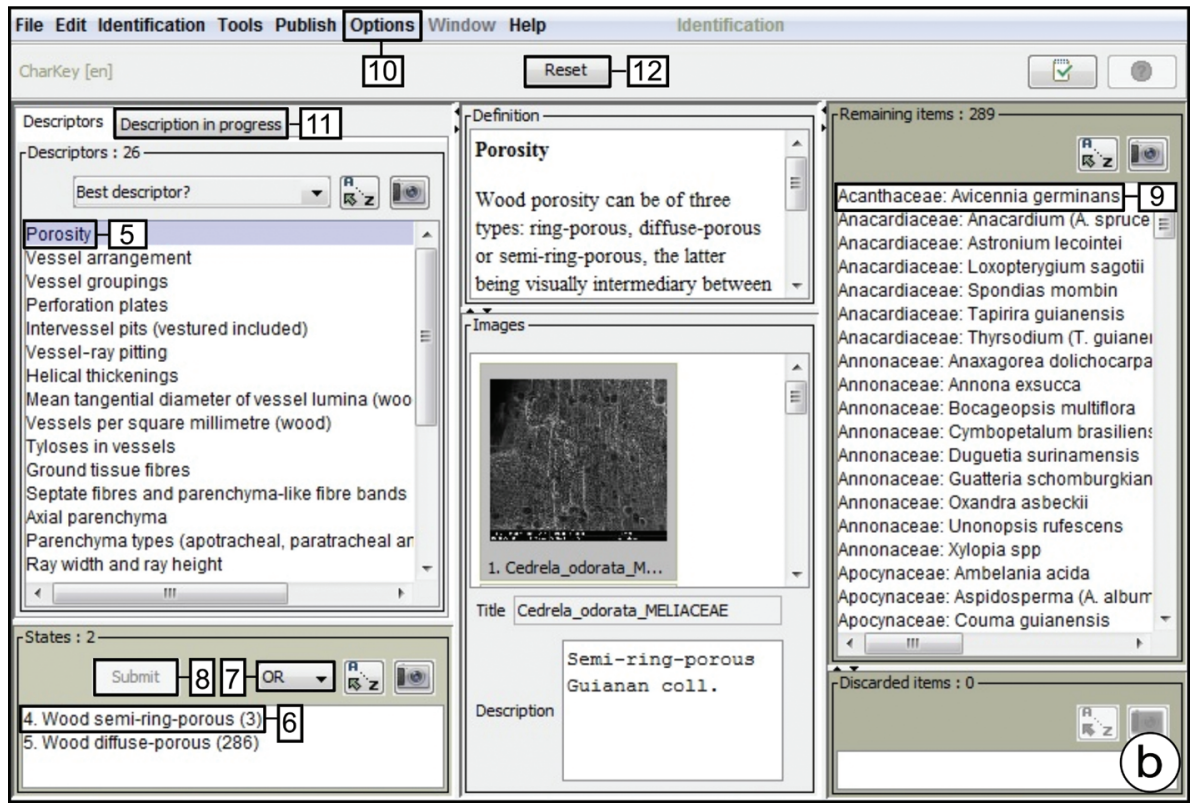

clicks on "submit" (8), the list of taxa corresponding to the selected features appears in the top right window. Click on one of them (9) to see the list of species in each genus present in French Guiana. Throughout the process, the mismatch threshold can be changed in the options (10) and the selected features can be seen and removed one by one by clicking on the "Description in progress" tab (11). The current search can be closed and a new identification started by pressing the "Reset" button (12). 
tree species of French Guiana (Molino et al. 2009). Furthermore, we have also added 8 species included in our reference collection which were not described in the references cited. The classification of families follows the Angiosperm Phylogeny Group (2016); that of Leguminosae (Fabaceae) follows that of the Legume Phylogeny Working Group (LPWG 2017). The genera and species taxonomy and nomenclature was updated to match the most recent accepted revisions of families and genera (Molino et al. 2009). The key contains no double entries under different synonyms. Species described in Détienne et al. (1982) that are not present in French Guiana (either native or introduced) were left out. Among the 507 species included in CharKey, about $2 \%$ are endemic to French Guiana and $16 \%$ are endemic to the Guiana Shield, which includes the Guianas (Guyana, French Guiana and Suriname) and adjacent parts of Venezuela, Brazil and Colombia.

The number of genera per family described in CharKey compared with what is currently known in French Guiana (Molino et al. unpublished data) is given by Figure 1a. The Leguminosae family has the highest number of genera (63) of which 48 are described in CharKey. In contrast, 25 of the 71 families are represented by a single genus. Figure $2 b$ gives the number of species per genus: $29 \%$ of the genera in French Guiana are represented by a single species (Molino et al. unpublished data) and the average is about 6 species per genus. The richest genera ( $>50$ species) are Pouteria, Sapotaceae (60 species), Inga, Leguminosae (59 species) and Eugenia, Myrtaceae (59 species).

\section{Charcoal anatomical features}

A total of 26 anatomical features (referred to as "descriptors" in Xper ${ }^{2}$ ) are recorded in CharKey, leading to 112 feature states (hereafter "states", like in Xper²). Most of the descriptors and their states were taken from the IAWA list of microscopic features for hardwood identification (Wheeler et al.1989); some were left out or refined depending on the peculiarities of charcoal (Table 1).

\section{Refined features}

Charcoal has fewer diagnostic features than wood, which makes identification even harder. Therefore, when possible, the remaining observable features need to be made more specific in order to improve identification and to avoid long lists of taxa at the end of the identification process. In CharKey, three IAWA features were refined. Feature 97 (ray width 1 to 3 cells) was split into three states (97a, 97b and 97c) corresponding to different ray width: 1-seriate, 2 -seriate or 3-seriate. If an unknown charcoal has mostly 2 -seriate rays, this means all taxa that usually have 1- or 3-seriate rays can be excluded. If the unknown charcoal presents a combination of 1- to 3-seriate rays, then the different states can be simply selected together. In the same way, feature 98 (larger rays commonly 4- to 10-seriate) was split into states 98 a and $98 \mathrm{~b}$, "larger rays commonly 4-seriate" and "larger rays commonly 5- to 10-seriate". Finally, feature 7 (vessels in diagonal and/or radial pattern) was split into $7 \mathrm{a}$ and $7 \mathrm{~b}$, corresponding respectively to vessels in diagonal pattern and vessels in radial pattern. 
Table 1. List of features included in CharKey.

Features 7, 97 and 98 were refined to better target the identification results. The three supplementary features are the presence of helical thickenings in axial parenchyma (observed in Chrysobalanaceae), multiseriate rays with long uniseriate marginal rows and crystals in included phloem. - Note: IAWA features regarding crystals are simplified because their specific location is not usually mentioned in the literature.

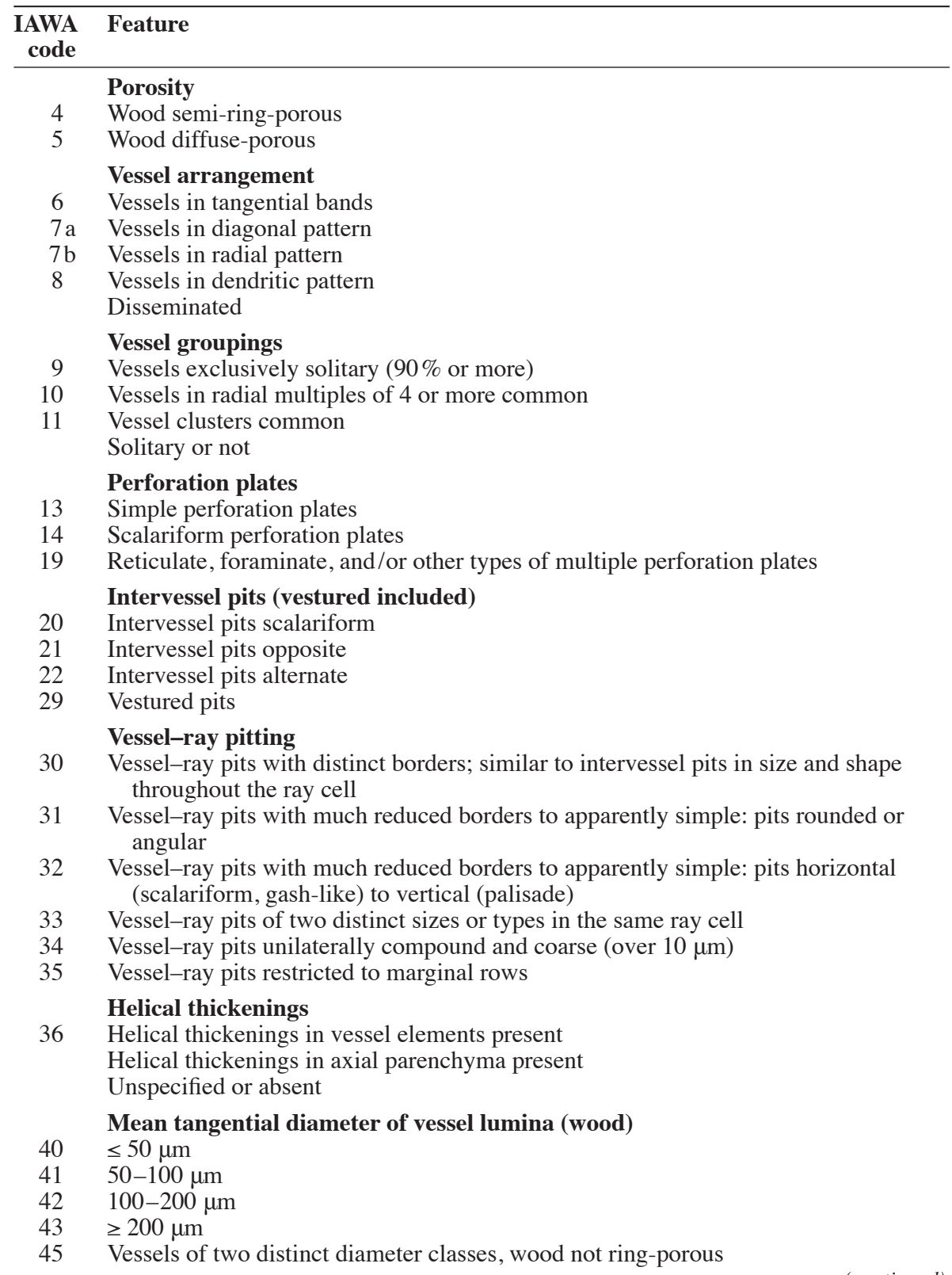




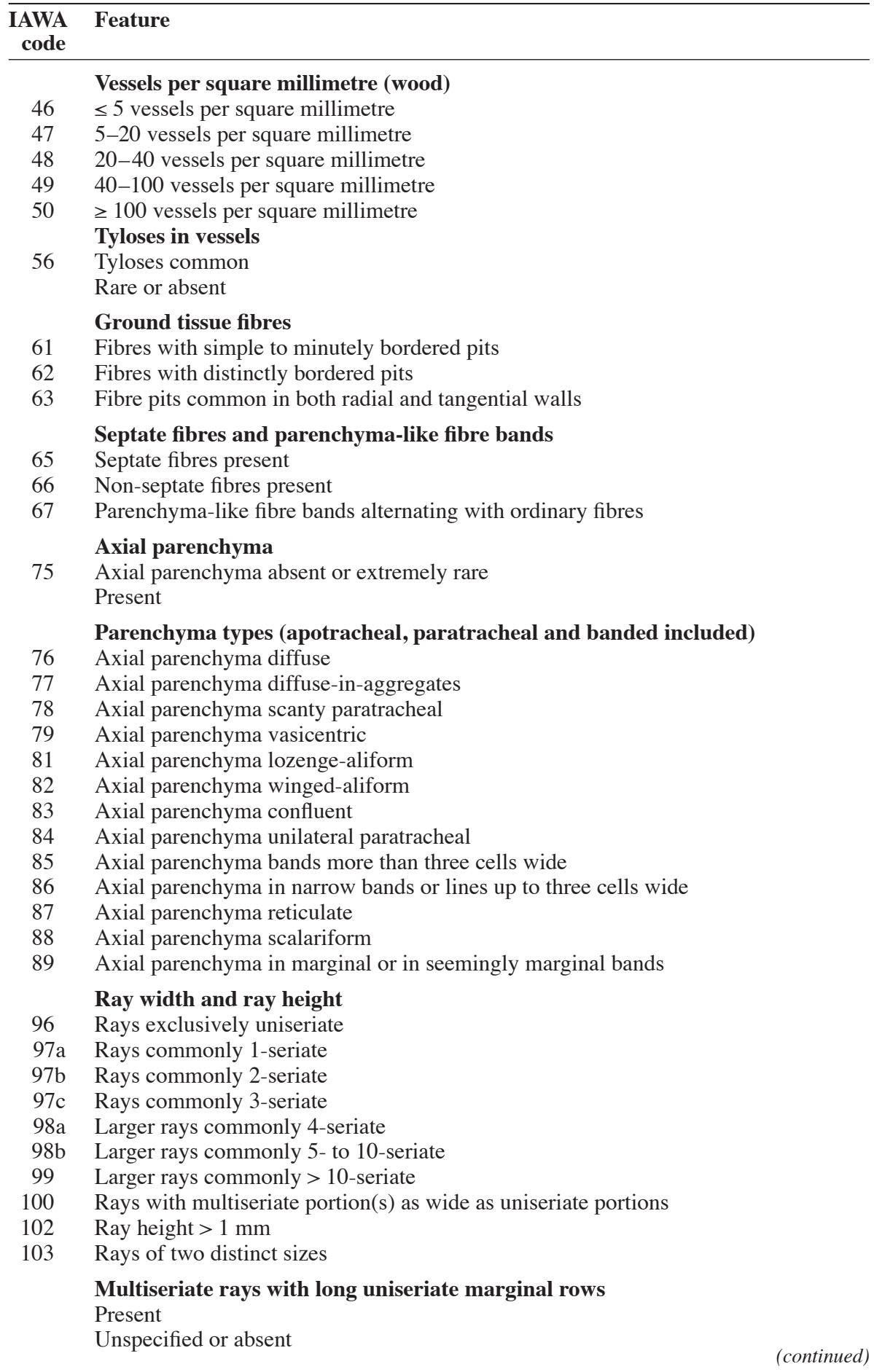




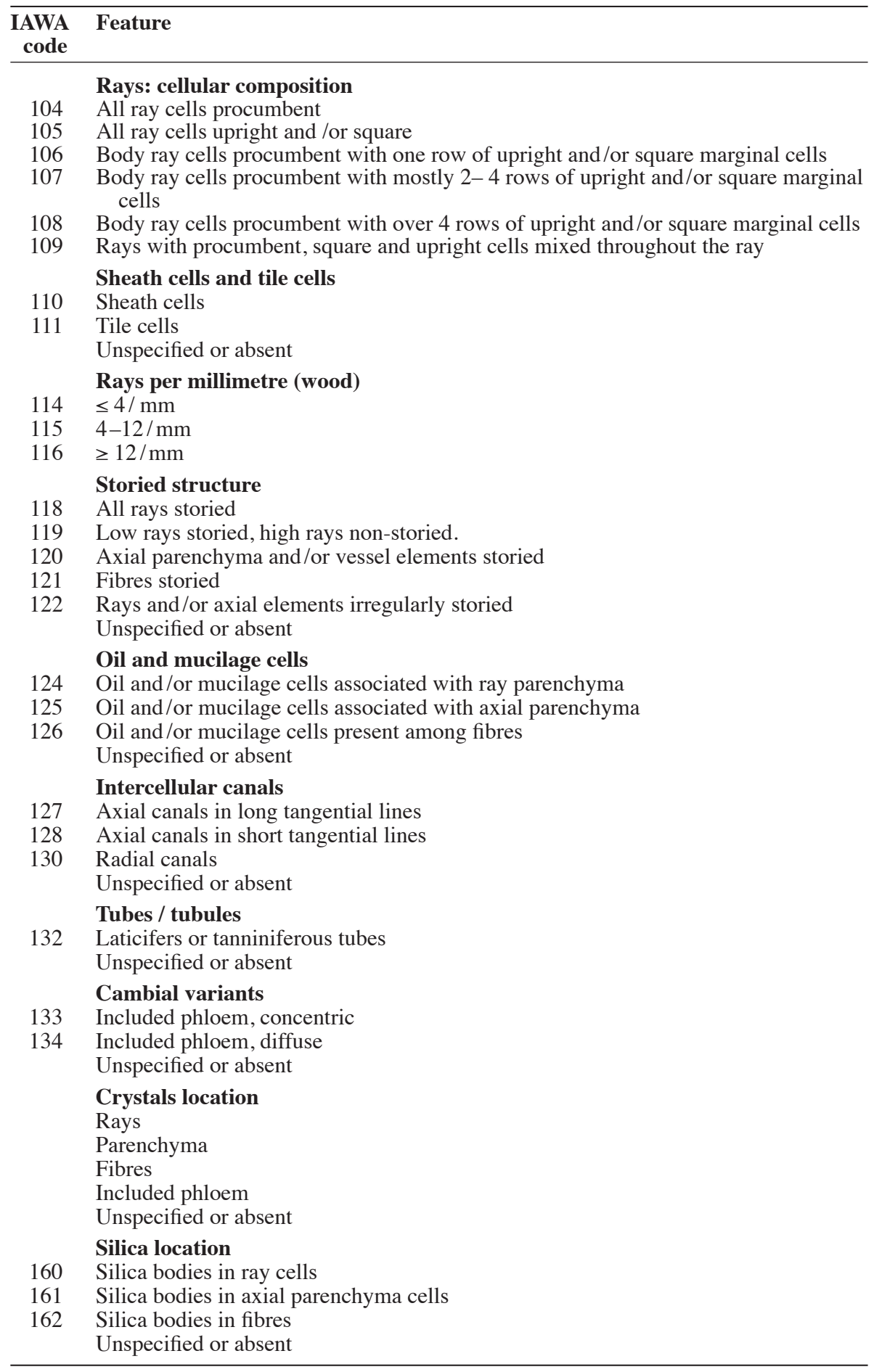




\section{Additional features}

A feature related to the appearance of the ray, as seen in tangential section, was added on the basis of the photographs in Détienne \& Jacquet (1983) to help discriminate between taxa: the presence of multiseriate rays with long uniseriate marginal rows. It includes heterogeneous and homogeneous rays and partly corresponds to the "heterogeneous type I" of Kribs (1935). Another supplementary feature is the presence of helical thickenings in the axial parenchyma, which were described in several genera of the Chrysobalanaceae (Ter Welle 1975; Détienne et al. 1982). In the same way, the presence of crystals in the included phloem of some species (Antonia ovata, Strychnos glabra and Mouriri spp.) led us to add another state to the descriptor "crystal location".

\section{Non-relevant features}

Features that are not useful for charcoal identification were not included in the key. Some anatomical features usually visible in wood may be not visible in charcoal as a result of carbonization. This includes deposits in vessels and features concerning color, density or smell. This also includes features that require maceration of the wood such as mean vessel element length, mean fiber length and vitreous silica. We also excluded features that are usually hard to see (vascular tracheids and the exact location of helical thickenings in vessels) or hard to count (the number of cells per parenchyma strand and the number of bars in scalariform perforation plates) in charcoal, especially in archeological material. Finally, charcoal shrinkage during carbonization can alter the outline of the vessel and the shape of alternate pits, so we did not include these features in CharKey.

\section{Features to be added in future versions}

Some features were not included in the present version because information was lacking for many species, but will be included in future versions. These features are thickness of the fiber wall, the number of ray tiers per axial millimeter and the types of crystals (druses, raphids, etc.). Finally, the size of intervessel pits will be added using measurements made on pit aperture, because the pit chamber is usually not visible on charcoal, maybe as a result of carbonization as suggested by Gonçalves et al. (2012).

\section{HOW TO USE THE IDENTIFICATION KEY}

\section{First view of CharKey through $\mathrm{Xper}^{2}$}

When the key is opened, the list of 26 descriptors appears in the top left window (Fig. 2a) (the descriptor indexes are generated automatically by Xper ${ }^{2}$ and are not linked with the IAWA code). When clicking on a descriptor (1), its states appear in the top right window and its definition in the bottom left window. (The state codes are those of IAWA). If the feature has poor diagnostic power, this is specified in the definition window. When clicking on a state (2), the corresponding definition appears in the bottom left window and the associated pictures can be seen by clicking on the "Images" tab (3). To start an identification, the user has to click on "Identification" in the tool bar (4). 


\section{Identification process}

The descriptors appear on the left, just above their different states with the number of corresponding taxa («items » in $\mathrm{Xper}^{2}$ ) in brackets (Fig. 2b). When clicking on a descriptor (5) or on a state (6), its definition and related images appear in the middle windows. To select several states, "ctrl" must be pressed. The user can choose the logical operator by clicking in the drop-down menu in the states window (7). We strongly advise to only use "OR" (default) or "AND" and to avoid using "NOT" because this could eliminate taxa by mistake. The genera recorded in CharKey contain specific variability: this means that, if a feature or a state is excluded during the identification process, it may exclude a genus including a matching species. For instance, if the user excludes feature state 32, then the genus Lecythis and all its species will be discarded, even those that do not present this feature state. The exclusion of features should only be used as a last step, to help discriminate the remaining items or when the absence is obvious (e.g. absence of included phloem). The user should also be careful not to exclude features such as radial canals or scalariform perforation plates which may be missing from small fragments. When the states are selected, the "Submit" button must be pressed (8) to refresh the list of corresponding items. The window on the right lists all the taxa included in the key: 274 genera plus species that were recorded independently of their genus because they were described under a synonym genus in Détienne et al. (1982) (see Supplementary Material for the revised nomenclature), giving 289 items. The user can see the list of species present in French Guiana for each genus by clicking on an item (9): the information will appear in the definition window, thereby allowing to assess the degree of uncertainty when identifying a genus. The habit and the relative abundance of the species described in CharKey are indicated in the Supplementary Material, giving a hint about which species are more likely to match the unknown sample. The discarded ones will appear in the bottom right window. When the selected states are common, the list of remaining taxa may be long. In these cases, the only way to move forward in the identification process is to switch to atlases and reference collections, which are irreplaceable resources. If the results do not match the sample observed, the number of permitted mismatches can be modified by clicking on "Options" (10), then "Identification" and "Mismatch threshold". The selected states can be seen and removed one by one throughout the identification process by clicking on the "Description in progress" tab (11). Finally, the "Reset" button (12) allows to clear all windows and start a new identification.

\section{Qualitative features and discriminant power}

To avoid misidentification, tyloses, silica and crystals should only be considered as diagnostic features when they are very abundant. In some woods, helical thickenings can also be observed even though previous descriptions fail to mention them. For example, Scheel-Ybert and Gonçalves (2017) describe the presence of helical thickenings in Tapirira (Anacardiaceae), whereas this feature is not mentioned in this genus by Détienne et al. (1982) or by Détienne and Jacquet (1983). The presence or absence of helical thickenings is a very useful diagnostic feature when identifying wood of temperate species; however, their relevance to tropical wood identification may be 
subject to debate (Baas 1973; Ter Welle 1975). For now, these features should only be considered as supporting information and consequently should not be given undue importance at the beginning of the identification process.

\section{Quantitative features and charcoal shrinkage}

Some quantitative features have to be considered with care because charring causes shrinkage, especially in the tangential direction due to the anisotropic behavior of charcoal (McGinnes Jr et al. 1971; Beall et al. 1974; Prior \& Gasson 1993). The impact of charring is particularly clear in the tangential diameter of vessel lumina, which is significantly reduced (Prior \& Gasson 1993; Gonçalves et al. 2012), especially in grouped vessels (Prior \& Gasson 1993). Although these studies found no statistical evidence for an effect of carbonization, either in the number of vessels per square millimeter, or in the number of rays per millimeter, such an effect cannot be excluded. It should therefore be kept in mind that a measurement made on charcoal can fall into one of the lower or higher categories when selecting states of the three quantitative features "tangential diameter of vessel lumina", "vessels per square millimeter" and "rays per millimeter", which were measured on wood.

\section{Expected outcome of the identification}

Anatomical descriptions were mostly recorded in CharKey at the genus level, because identification at the species level is rare, especially in the tropics. At the same time, some families are anatomically homogeneous, which means it is very difficult to even distinguish between genera based on wood anatomy. The level at which identification is possible has therefore to be taken into consideration. Like in Détienne et al. (1982), the descriptions of genera known in French Guiana are recorded separately in the key. However, it should be kept in mind that it may be risky to try to identify a specimen to the genus level if it belongs to one of the following families or subfamilies: Anacardiaceae/Burseraceae pro parte, Annonaceae, Bombacoideae pro parte, Chrysobalanaceae, Combretaceae, Humiriaceae, Lauraceae, Lecythidaceae pro parte, Leguminosae pro parte, Melastomataceae pro parte, Moraceae pro parte, Myrtaceae and Sapotaceae. The user can check which feature could help to distinguish a genus by selecting all the items proposed as results, by right-clicking and selecting "comparison". This opens a window in which the discriminant features appear in blue. It is up to the user to decide whether the proposed features are really discriminant or not. For example, it may be not advisable to distinguish one genus from another on the basis of the "presence of tyloses", as explained in the "Qualitative features and discriminant power" section above. Nevertheless, identification at the species level is sometimes possible, for example, when a family is represented by a single species (e.g. Goupia glabra, Goupiaceae or Hernandia guianensis, Hernandiaceae) or when a species within a genus is distinct from the others (e.g. Eugenia patrisii, Myrtaceae).

\section{APPLICATION OF THE IDENTIFICATION KEY}

CharKey aims to make the identification process faster and easier for charcoal found in French Guiana. As its database is local, the outputs proposed by the key will only 


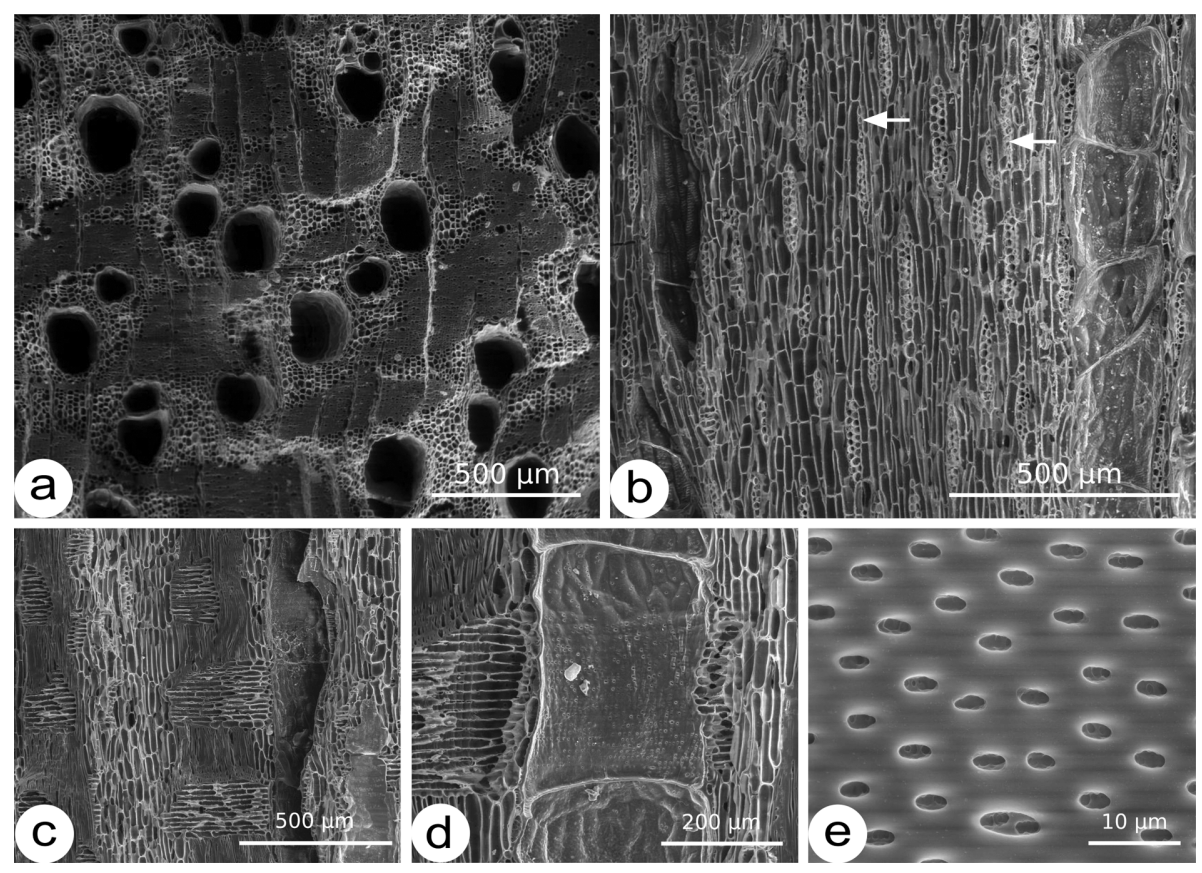

Figure 3. Transverse (a), tangential longitudinal (b, e) and radial longitudinal (c, d) sections of Recordoxylon speciosum (Caesalpinioideae). - a: Parenchyma mostly aliform and confluent. b: 2-seriate rays, some of which have uniseriate marginal portions (arrows). - c: Homogeneous rays. $-\mathrm{d}$ : Vessel-ray pits similar to intervessel pits in shape and size. - e: Intervessel pits vestured.

contain taxa that are actually present in French Guiana, whereas InsideWood gives outputs for the whole of "tropical South America". The list of taxa covering this area includes very many species that are not present in French Guiana, which consequently requires the user to check their geographical distribution. This can be a quite laborious process, especially if the unknown sample belongs to a huge anatomically homogeneous family like the Leguminosae. As an illustration, we took a charcoal from the Guianan reference collection belonging to this family: Recordoxylon speciosum (Fig. 3) and compared the outputs given by InsideWood and CharKey. The features used in the search with InsideWood are 13p 22p 29p 30p 40a 49a 50a 75a 80p 83p 97p 104p 186p and those used with CharKey are, in order: "Vessel arrangement: Diffuse"; "Vessel groupings: Solitary or not"; "Axial parenchyma: Present"; "Parenchyma types: 81 OR 82 OR 83"; "Rays: cellular composition: 104"; "Vessel-ray pitting: 30"; "Intervessel pits: 22 AND 29"; "Ray width and ray height: 97b"; "Multiseriate rays with long uniseriate marginal rows: Present". With InsideWood, Recordoxylon speciosum appears in the search results among 93 descriptions covering 50 genera (accessed on August 29, 2018). Among these, there are 56 descriptions of species not present in French Guiana. With CharKey, it appears in a more restricted list of 10 items covering 9 genera. States $97 \mathrm{~b}$ and "Multiseriate rays with long uniseriate marginal 


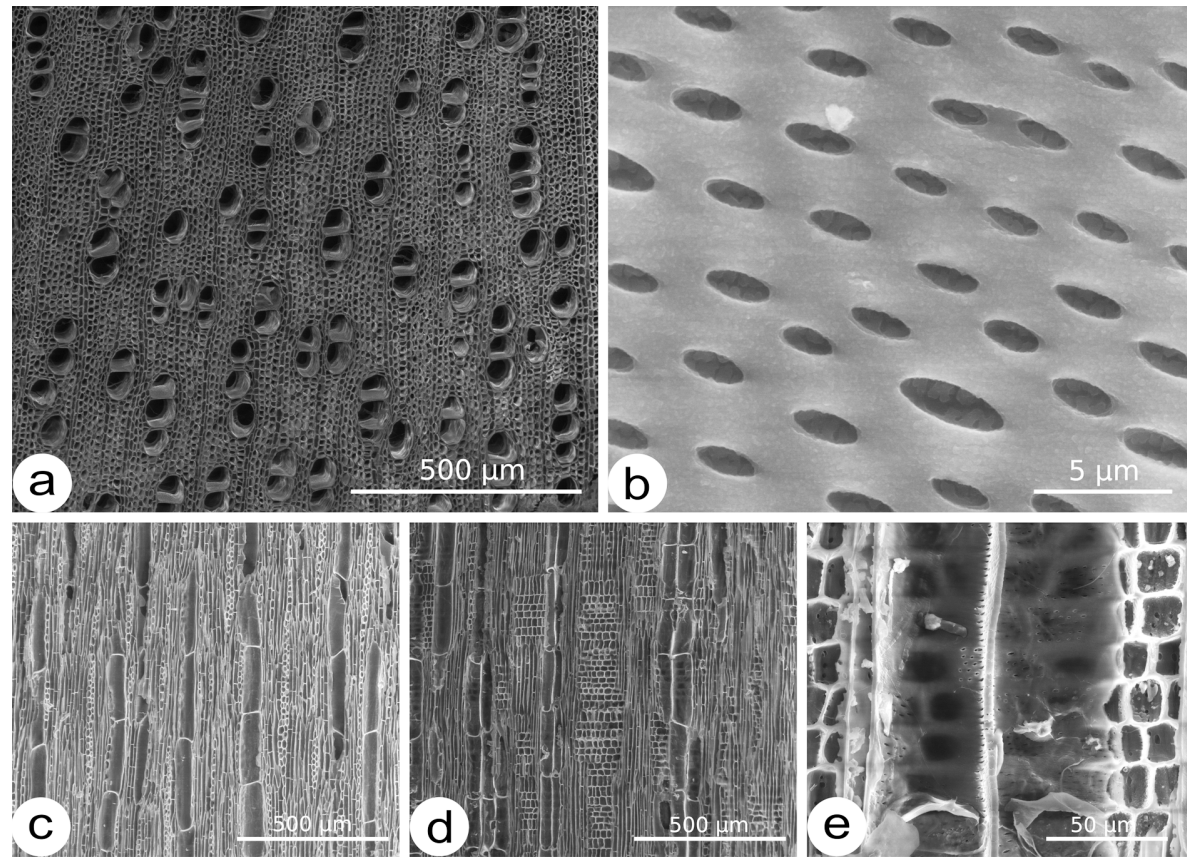

Figure 4. Transverse (a), tangential longitudinal (b, c) and radial longitudinal (d, e) sections of Bixa orellana (Bixaceae). - a: Parenchyma diffuse-in-aggregates. - b: Intervessel pits vestured. c: 2-seriate rays with low rays and parenchyma storied. $-\mathrm{d}$ : Heterogeneous rays. - e: Vessel-ray pits similar to intervessel pits in shape and size.

rows: Present" each make it possible to discard 14 items, thereby revealing their usefulness in the efficiency of the key. By focusing only on local species, the key allows the user to directly compare results with a reference collection and atlases without sorting them according to species distribution.

Nevertheless, even if the unknown sample is present in French Guiana, we still recommend comparing the results with InsideWood, especially with taxa for which identification is problematic. If the outputs are different, a misidentification will be avoided. This could be the case if the sample to be identified is not yet described in this version of CharKey. For instance, the Bixaceae family is absent in this version. We compared the results in CharKey and in InsideWood using the example of Bixa orellana, a cultivated species introduced in French Guiana (Fig. 4). The 32 results given by InsideWood (search criteria 9a 13p 22p 30p 40a 43a 46a 76p 77p 97p 104a 105a 118p 186p with 1 allowable mismatch) include Bixa orellana (accessed on August 29, 2018) whereas CharKey cannot give correct results. Depending on the order in which the search criteria were selected, the search will end either by a list that obviously does not include the species to be identified or by no results at all. For instance, if the first three search criteria are (in order): "Vessel arrangement: Diffuse"; "Vessel groupings: Solitary or not" and "Storied structure: 119 AND 120", the key will propose five items belonging to Malvaceae. After comparison with a reference collection or atlases, the 
user will see that these species do not match the "unknown" sample. That is why, in the case of doubt, using another identification tool like InsideWood to compare results is highly recommended. For now, 12 Guianan woody families have no representatives in CharKey and about $30 \%$ of the species described in it have no anatomical description in InsideWood or are only represented by pictures. Both identification tools will be further enriched with descriptions of more Guianan wood.

\section{CONCLUSION}

CharKey is the first step in the making of a larger identification key for Guianan wood charcoals. Its purpose is to make identifications faster and easier. It cannot - and is not intended to - replace atlases and reference collections. CharKey is a complementary tool to be used as a first step in the identification process, as it guides users through the reference species under consideration. Knowing the diversity of the Guianan woody flora, this key will save time. Although it is not exhaustive, CharKey already covers the majority of woody families known in French Guiana. It will be further improved with the addition of new native species along with introduced and cultivated species. More anatomical features will also be added or refined to improve charcoal identification. This will be possible through the study of quantitative features on charcoal specimens from the reference collection as already carried out by Scheel-Ybert and Gonçalves (2017) with Brazilian species. Lastly, new photographs will be included to illustrate species present in CharKey as well as the anatomical diversity that can be found at genus - and even at species - level.

\section{ACKNOWLEDGEMENTS}

CharKey is a case study of the LongTIme project. We acknowledge an Investissement d'Avenir grant from the Agence Nationale de la Recherche (CEBA: ANR-10-LABX-25-01). We thank Julien Engel for his advice on the use of $\mathrm{Xper}^{2}$, Isabel Figueiral for useful feedback on previous versions of the manuscript and during the elaboration of the key, Patrick Langbour for his help on anatomical issues, Antoine Affouard for rapidly resizing photographs with no loss in quality and Christophe Tardy for enthusiastic comments on the key project.

\section{REFERENCES}

APG. 2016. An update of the Angiosperm Phylogeny Group classification for the orders and families of flowering plants: APG IV. Bot. J. Linn. Soc. 181: 1-20. https://doi.org/10.1111/ boj.12385.

Baas P. 1973. The wood anatomical range in Ilex (Aquifoliaceae). Blumea 21: 193-258.

Bal M-C, Rendu C, Ruas M-P, Campmajo P. 2010. Paleosol charcoal: Reconstructing vegetation history in relation to agro-pastoral activities since the Neolithic. A case study in the Eastern French Pyrenees. J. Archaeol. Sci. 37: 1785-1797. http://dx.doi.org/10.1016/j. jas.2010.01.035.

Beall FC, Blankenhorn PR, Moore GR. 1974. Carbonized wood-physical properties and use as an SEM preparation. Wood Sci. 6: 212-219.

Dechamps R. 1979. Étude anatomique de bois d'Amérique du Sud. Vol. I. Acanthaceae à Lecythidaceae. Musée Royal de l'Afrique Centrale, Tervuren. 
Dechamps R. 1980. Étude anatomique de bois d'Amérique du Sud. Vol. II. Leguminosae. Musée Royal de l'Afrique Centrale, Tervuren.

Dechamps R. 1985. Étude anatomique de bois d'Amérique du Sud. Vol. III. Linaceae à Zygophyllaceae. Musée Royal de l'Afrique Centrale, Tervuren.

Détienne P, Jacquet P. 1983. Atlas d'identification des bois de l'Amazonie et des régions voisines. Centre Technique Forestier Tropical, Nogent-sur-Marne.

Détienne P, Jacquet P, Mariaux A. 1982. Manuel d'identification des bois tropicaux. Tome 3: Guyane française. Centre Technique Forestier Tropical, Nogent-sur-Marne.

Dotte-Sarout E. 2011. Evaluating methods and results for the application of anthracology to high diversity and high endemism environments: Case study in the Tiwaka Valley, northeastern Grande Terre of New Caledonia. SAGVNTVM Extra 11: 41-42.

Gonçalves TAP, Marcati CR, Scheel-Ybert R. 2012. The effect of carbonization on wood structure of Dalbergia violacea, Stryphnodendron polyphyllum, Tapirira guianensis, Vochysia tucanorum, and Pouteria torta from the Brazilian cerrado. IAWA J. 33: 73-90. DOI: 10.1163/22941932-90000081.

Heinz C, Thiébault S. 1998. Characterization and Palaeoecological significance of archaeological charcoal assemblages during late and post-glacial phases in southern France. Quat. Res. 50: 56-68. DOI: 0033-5894/98.

Höhn A, Neumann K. 2018. Charcoal identification in a species-rich environment: The example of Dibamba, Cameroon. IAWA J. 39: 87-113. DOI: 10.1163/22941932-20170195.-

Hubau W, Van den Bulcke J, Kitin P, Brabant L, Van Acker J, Beeckman H. 2013. Complementary imaging techniques for charcoal examination and identification. IAWA J. 34: 147-168. DOI: 10.1163/22941932-00000013.

Hubau W, Van den Bulcke J, Kitin P, Mees F, Van Acker J, Beeckman H. 2012. Charcoal identification in species-rich biomes: A protocol for Central Africa optimised for the Mayumbe forest. Rev. Palaeobot. Palynol. 171: 164-178. DOI: 10.1016/j.revpalbo.2011.11.002.

InsideWood. 2004-onwards. Published on the Internet. http://insidewood.lib.ncsu.edu/search [accessed in 2018].

Kribs DA. 1935. Salient lines of structural specialization in the wood rays of dicotyledons. Bot. Gaz. 96: 547-557. https://doi.org/10.1086/334500.

LPWG. 2017. A new subfamily classification of the Leguminosae based on a taxonomically comprehensive phylogeny. Taxon 66: 44-77. https://doi.org/10.12705/661.3.

McGinnes Jr EA, Kandeel SA, Szopa PS. 1971. Some structural changes observed in the transformation of wood into charcoal. Wood Fiber 3: 77-83.

Molino JF, Sabatier D, Prévost MF, Frame D, Gonzalez S, Bilot-Guérin V. 2009. Etablissement d'une liste des espèces d'arbres de la Guyane française. IRD Cayenne.

Morin-Rivat J, Fayolle A, Gillet J-F, Bourland N, Gourlet-Fleury S, Oslisly R, Bremond L, Bentaleb I, Beeckman H, Doucet J-L. 2014. New evidence of human activities during the Holocene in the lowland forests of the northern Congo Basin. Radiocarbon 56: 209-220. DOI: $10.2458 / 56.16485$.

Prior J, Gasson P. 1993. Anatomical changes on charring six African hardwoods. IAWA J. 14: 77-86. DOI: $10.1163 / 22941932-90000579$.

Scheel-Ybert R. 2016. Charcoal collections of the world. IAWA J. 37: 489-505. DOI: 10.1163/ $22941932-20160148$.

Scheel-Ybert R, Beauclair M, Buarque A. 2014. The forest people: landscape and firewood use in the Araruama region, southeastern Brazil, during the late Holocene. Veg. Hist. Archaeobotany 23: 97-111. https://doi.org/10.1007/s00334-013-0397-z.

Scheel-Ybert R, Gonçalves TAP. 2017. Primeiro atlas antracológico de espécies Brasileiras / First anthracological atlas of Brazilian species. Museu Nacional, Rio de Janeiro. 
Scheel-Ybert R, Gouveia SEM, Pessenda LCR, Aravena R, Coutinho LM, Boulet R. 2003. Holocene palaeoenvironmental evolution in the São Paulo State (Brazil), based on anthracology and soil $\delta^{13} \mathrm{C}$ analysis. The Holocene 13: 73-81. DOI: 10.1191/0959683603hl596rp.

Talon B, Carcaillet C, Thinon M. 1998. Études pédoanthracologiques des variations de la limite supérieure des arbres au cours de l'Holocène dans les alpes françaises. Géographie Phys. Quat. 52: 195. DOI: 10.7202/004875ar.

Ter Welle BJH. 1975. Spiral thickenings in the axial parenchyma of Chrysobalanaceae. Acta Bot. Neerlandica 24: 397-405. https://doi.org/10.1111/j.1438-8677.1975.tb01030.x

Touflan P, Talon B, Walsh K. 2010. Soil charcoal analysis: a reliable tool for spatially precise studies of past forest dynamics: a case study in the French southern Alps. The Holocene 20: 45-52. DOI: 10.1177/0959683609348900.

Ung V, Dubus G, Zaragüeta-Bagils R, Vignes-Lebbe R. 2010. Xper²: introducing e-taxonomy. Bioinformatics 26: 703-704. DOI: 10.1093/bioinformatics/btp715.

Wheeler EA. 2011. InsideWood - a web resource for hardwood anatomy. IAWA J. 32: 199-211. DOI: $10.1163 / 22941932-90000051$.

Wheeler EA, Baas P, Gasson PE. 1989. IAWA list of microscopic features for hardwood identification. IAWA Bull. n.s. 10: 219-332. https://doi.org/10.1002/fedr.19901011106. 